\title{
Analisis Data Resistivitas Dipole-dipole Untuk Identifikasi Dan Perhitungan Sumber Daya Asbuton Di Daerah Kabungka, Pasarwajo, Pulau Buton, Sulawesi Tenggara.
}

\author{
Imam Suyanto, Agung Setyo Utomo \\ Program Studi Geofisika FMIPA UGM \\ Sekip Utara, Bulaksumur, Yogyakarta \\ imamsuyanto@ugm.ac.id
}

\begin{abstract}
Abstrak - Telah dilakukan penelitian sebaran batuan aspal buton (asbuton) dengan menggunakan metode resistivitas dipoledipole. Penelitian ini bertujuan untuk memetakan sebaran asbuton secara 2-D maupun 3-D seta menghitung cadangan asbuton daerah penelitian. Penentuan sebaran asbuton didasarkan pada perbedaan nilai resistivitas asbuton dengan batuan di sekitarnya. Pengolahan dan pemodelan data resistivitas menggunakan software Res2Dinv, sehingga didapatkan model penampang resistivitas asbuton. Penentuan nilai asbuton daerah penelitian didasarkan pada lintasan yang melewati singkapan asbuton, yaitu antara 90 - 600 Sm. Sebaran asbuton setelah dilakukan pemodelan secara 2-D maupun 3-D banyak terdapat pada Formasi Tondo dengan bentuk asbuton berupa bolder dengan ketebalan bervariasi antara 1 - 40 meter. Besar potensi cadangan asbuton dimasukkan dalam 2 kategori yaitu : cadangan terukur dan cadangan tereka. Besar potensi asbuton pada cadangan terukur dengan volume 6,1 juta meter kubik (m3) adalah 17,0 juta ton. Besar potensi asbuton cadangan tereka dengan volume 22,2 juta meter kubik (m3) adalah 62,1 juta ton.
\end{abstract}

Kata kunci: Asbuton, dipole-dipole, resistivitas

\begin{abstract}
Rock asphalt of buton (asbuton) research using dipole-dipole arrays resistivity method has been done. The purpose of this reserach is to modelling the distribution of asbuton reserve, based on different resitivity value between asbuton with the surroundings rocks. Processing and modelling resistivity value is using Res2Dinv software and the result is 2-D section resistivity of asbuton. True resistivity value which based on asbuton outcrop in research area is within $90-600 \Omega m$ in range. Asbuton distribution is known exist at Tondo Formation in boulders with variative thickness between 1 - 40 metres in range after inverse modeling. Asbuton potential reserve could be classified into 2 categories, which are : measureable reserve and possibility reserve. Asbuton potential measurable reserve with volume 16,1 millions of metre cubic (m3) in mass is 17,0 millions of tons. Asbuton potential at possibility reserve with 2,2 millions of metre cubic (m3) in volume is 62,1 millions of tons.
\end{abstract}

Key words: Asbuton, dipole-dipole, resistivity

\section{PENDAHULUAN}

Potensi asbuton yang diperkirakan memiliki cadangan yang cukup besar membuat para produsen untuk kembali menggalakkan kegiatan eksplorasi. Kegiatan eksplorasi geofisika yang digunakan untuk survey perkiraan daerah yang berpotensi aspal dilakukan dengan dua cara, yaitu eksplorasi seismik dan geoelektrisitas, yang selanjutnya akan disebut dengan resistivitas.

Kegiatan eksplorasi yang dilakukan pada survey saat ini menggunakan metode resistivitas. Keunggulan metode resistivitas adalah mempunyai kemampuan menampilkan variasi dari asbuton secara vertikal maupun horizontal dengan cukup baik di bawah permukaan bumi dan kemudahan dalam hal akomodasi dan biaya survey. Metode resistivitas dilakukan untuk menganalisis variasi dari nilai resistivitas batuan aspal dengan batuan di sekitarnya. Resistivitas yang tercatat menunjukkan adanya kandungan bitumen pada batuan. Asbuton yang berbitumen tinggi akan menunjukkan nilai resistivitas yang relatif lebih tinggi dari batuan sekitarnya.
Pemodelan secara 2-D maupun 3-D berdasarkan nilai resistivitas akan memperlihatkan persebaran asbuton pada daerah penelitian. Pemodelan tersebut akan mampu memperhitungkan besar cadangan dari asbuton.

\section{A. Tujuan Penelitian}

Tujuan dari penelitian ini adalah:

1. Memetakan keberadaan asbuton di bawah permukaan berdasarkan nilai resistivitas asbuton secara 2-D maupun 3-D.

2. Menghitung cadangan batuan aspal yang digunakan dalam pengembangan potensi cadangan aspal pada daerah penelitian.

\section{B. Lokasi dan Waktu Penelitian}

Lokasi penelitian secara administratif terletak di daerah Kabungka, Desa Waangu - Angu, Kecamatan Pasarawajo, Kabupaten Buton, Provinsi Sulawesi Tenggara. Secara geografis terletak pada $122^{0} 43^{\prime}-122^{\circ} 49^{\prime}$ BT dan $5^{0} 22^{\prime}$ $5^{0} 28^{\prime}$ LS. Lokasi penelitian diperlihatkan pada gambar 1 . 
Waktu pengambilan data dilakukan pada 29 Oktober - 10 November 2008.

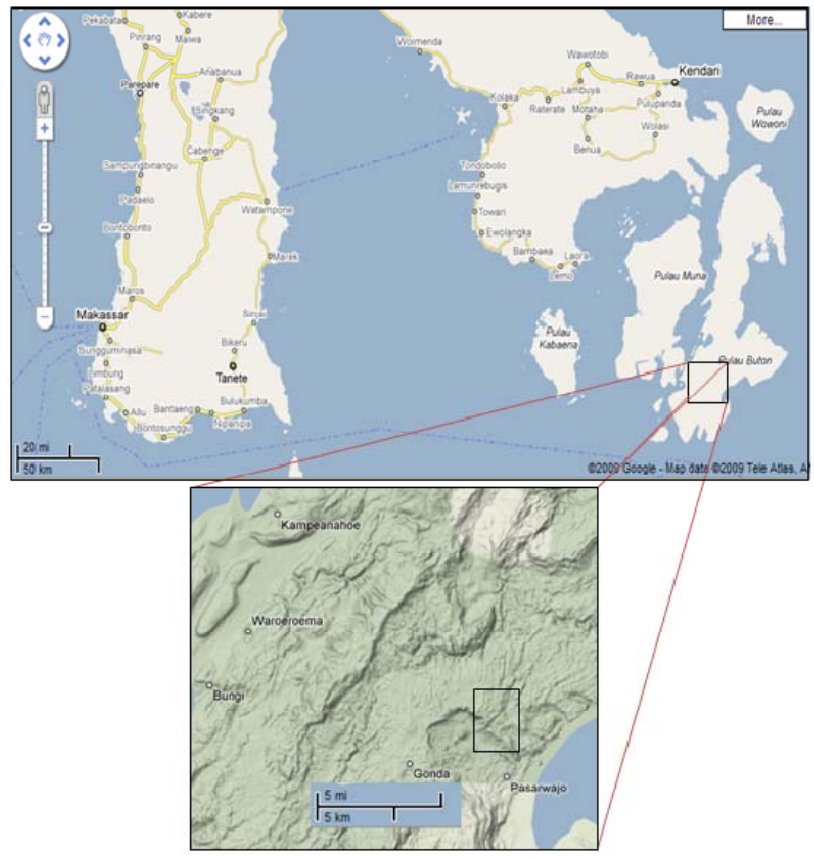

Gambar 1. Peta Wilayah P.Buton [10].

\section{Tinjauan Pustaka}

\section{C.1. Definisi Aspal}

Aspal merupakan bitumen yang secara umum merupakan sekelompok material yang terbentuk dari campuran hidrokarbon yang dapat dilebur (fusible) dan mencair (soluble) dalam karbon bisulfida [5].

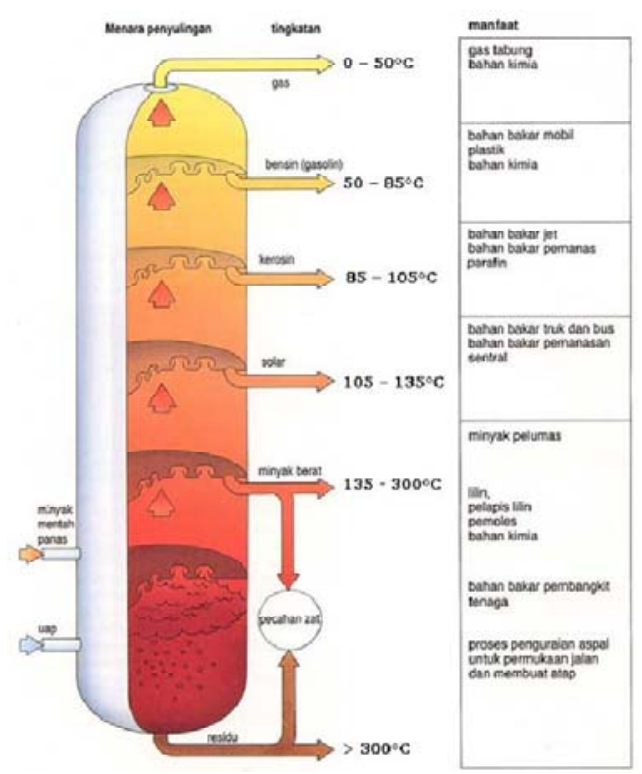

Gambar 2. Kolom fraksinasi minyak mentah [8].
Aspal minyak diperoleh dari penyulingan minyak bumi dengan berbagai kadar, volume lebih besar dan lebih ekonomis daripada aspal alam. Adanya variasi kadar ini memungkinkan dipakainya aspal diberbagai industri, sehingga kedudukan aspal alam banyak diganti oleh aspal minyak. Proses pembentukan aspal minyak diperlihatkan pada gambar 2.

Aspal batu buton (asbuton) adalah aspal alam yang terdapat di P.Buton, jenisnya adalah jenis rock asphalt, yaitu batuan yang terimpregnasi oleh aspal. Batuan induknya adalah batugamping. Partikel asbuton terdiri dari mineral, bitumen dan air, berwarna hitam kecoklat-coklatan, porous dan relatif ringan. Contoh rembesan dari aspal alam di P.Buton diperlihatkan pada gambar 2.2. Asbuton yang diekstraksi dapat dipisahkan antara mineral dengan bitumennya. Kadar aspal (bitumen) dari asbuton bervariasi dari 10 sampai $40 \%$ [3].

\section{C.2. Genesa Aspal}

Proses dari terjadinya asbuton hingga rembesan aspal mampu muncul ke permukaan bumi sampai saat ini masih terus diteliti oleh para ahli. Kejadian tektonik yang kompleks di daerah Sulawesi terutama di lengan bagian Tenggara, turut berperan dalam proses kejadian aspal tersebut. Secara umum, kejadian asbuton dipengaruhi oleh adanya aktivitas tektonik terhadap minyak bumi yang diduga semula terkandung dalam batuan induk, kemudian bermigrasi melalui dasar dan mengimpregnasi batuan sekitarnya, yaitu batugamping dan batupasir. Proses migrasi yang berjalan lambat mengakibatkan fraksi ringan dari minyak bumi menguap sedangkan fraksi berat bersatu dengan batuan yang dilewati dan membentuk aspal alam buton [1].

\section{Geologi Daerah Penelitian}

D.1. Stratigrafi Regional P.Buton

Geologi regional P.Buton telah banyak dibahas oleh beberapa peneliti, antara lain oleh [2, 4]. Wilayah di sepanjang anjungan kepulauan Buton - Tukang Besi disusun oleh kelompok batuan Mesozoikum berumur Trias hingga Kapur Atas hingga Paleosen dan kelompok batuan Kenozoikum berumur Tersier dan Kuarter.

Kelompok batuan tertua di P.Buton meliputi komplek batuan metamorf, meliputi Formasi Mukito dan Formasi Lakansai (dikenal dengan Formasi Doole). Formasi Mukito terdiri atas batuan metamorf sekis, filit dan batugamping kristalin. Formasi Lakansai terdiri dari runtuhan batuan metamorf berderajat rendah, yaitu batuan metamorf kwarsit mikaan yang berselingan dengan filit dan batusabak

Kelompok batuan Mesozoikum terdiri atas Formasi Winto, Formasi Rumu, dan Formasi Tobelo. Kelompok batuan sedimen yang termasuk batuan Kenozoikum kemudian menutupi sebagian besar P.Buton yang terdiri atas Formasi Tondo, Formasi Sampolakosa, dan Formasi Wapulaka yang diendapkan pada Miosen Awal hingga Pliosen Akhir Plistosen. Peta geologi Buton pada gambar 3. 


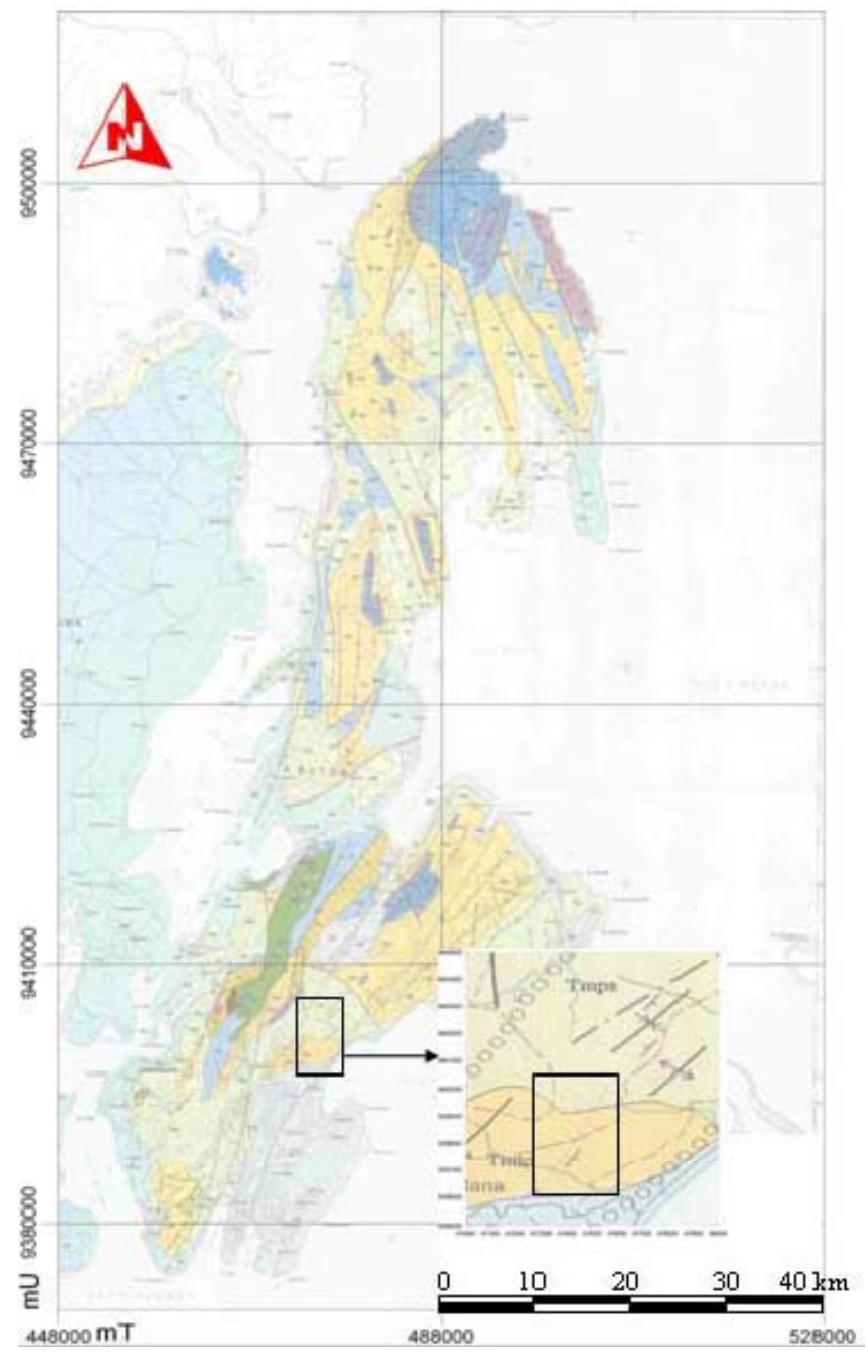

Gambar 3. Peta Geologi P.Buton [4].

\section{D.2. Stratigrafi Daerah Penelitian}

Urutan pengendapan pada daerah penelitian menurut [6] pada gambar 2.3 meliputi formasi berikut :

1. Formasi Tondo

Formasi Tondo sebagian besar tersingkap di bagian selatan dan sedikit di bagian utara P.Buton, yang dicirikan oleh perselingan antara konglomerat, batupasir, dan batulempung, serta di bagian bawah batugamping terumbu.

Anggota batugamping dari Formasi Tondo dicirikan oleh batugamping terumbu, yang mengandung banyak foraminifera bentos dan koral. Anggota ini menempati bagian paling bawah dari Formasi Tondo yang kemudian tertutup oleh konglomerat dan batupasir kerikilan.

Formasi Tondo berumur Miosen Tengah sampai Miosen Akhir, terendapkan pada lingkungan neritik hingga batial bawah. Rembesan minyak dan aspal banyak ditemukan dalam Formasi ini. Tebal Formasi diperkirakan lebih dari 1300 meter, banyak ditemukan di sebelah tenggara P.Buton [4].

\section{Formasi Sampolakosa}

Formasi Sampolakosa terdiri dari napal dan batupasir gampingan dengan sisipan kalkarenit berlapis tipis. Napal berwarna abu-abu terang, kompak, dan umumnya masif sampai berlapis, dipisahkan oleh sisipan tipis kalkarenit. Formasi Sampolakosa menutupi secara selaras Formasi Tondo.

Formasi Sampolakosa diendapkan pada lingkungan neritik hingga batial, dengan umur Miosen Atas hingga Pliosen Bawah. Rembesan minyak dan aspal banyak ditemukan pada Formasi ini di kampung Kabungka, Pasarwajo dan Lasalimu [4].

\section{E. Tinjauan Geofisika}

Penelitan geofisika yang pernah dilakukan untuk mengetahui jangkauan nilai resistivitas asbuton di Buton Selatan, yaitu: [3] melakukan penelitian menggunakan metode resistivitas sounding konfigurasi Wenner Schlumberger. Hasil pengukuran menunjukkan bahwa resistivitas singkapan asbuton (asbuton) antara 44 - $166 \Omega \mathrm{m}$. Nilai resistivitas yang cenderung naik dapat diinterpretasikan bahwa kandungan bitumennya lebih tinggi.

Penelitian dari Hamzah, belum memperlihatkan persebaran asbuton secara 3-D dan terbatas pada Formasi Winto, yang mempunyai umur lebih tua sehingga aspal tidak banyak terkumpul di Formasi ini, dimungkinkan aspal telah bermigrasi ke arah Formasi batuan yang lebih muda, terbentuk di atasnya dan mempunyai porositas yang lebih baik. Penelitian dengan metode resistivitas dipole-dipole dengan lintasan membentuk format grid dan pada Formasi yang berbeda, akan memperlihatkan persebaran asbuton secara 3-D, juga kandungan aspal pada batuan semakin besar.

\section{DASAR TEORI}

Resistivitas merupakan salah satu sifat fisis yang dimiliki batuan, yaitu, kemampuan untuk dilewati arus listrik, jika batuan makin sukar dilewati oleh arus listrik maka besarnya tahanan yang diberikan oleh batuan tersebut semakin besar. Masing-masing jenis batuan memiliki nilai resistivitas yang hampir sama, untuk batuan beku dan metamorf cenderung memiliki kisaran nilai resistivitas yang besar $(1000-108 \Omega \mathrm{m}$ untuk batuan beku dan $10-108 \Omega \mathrm{m}$ untuk sebagian batuan metamorf), sedangkan untuk batuan sedimen kisaran nilainya kurang dari $1000 \Omega \mathrm{m}$, bergantung oleh kandungan fluida dalam pori-nya.

\section{A. Teori Dasar Resistivitas}

Hubungan antara beda potensial, arus dan hambatan listrik, dikemukakan dalam Hukum Ohm, sebagai berikut [7]:

$$
R=\Delta V / I
$$

dengan $R=$ hambatan $(\Omega), I=$ kuat arus (Ampere), $\Delta V=$ beda potensial (Volt). 
Penjalaran arus dalam sebuah medium homogen, diberikan ilustrasi dalam gambar 4. Persamaan tahanan jenis diberikan pada persamaan (2).

$$
R=\rho L / A
$$

dengan $\rho=$ resistivitas $(\Omega \mathrm{m}), R=$ hambatan $(A=$ luas penampang (m2) dan $L=$ panjang penampang $(\mathrm{m})$.

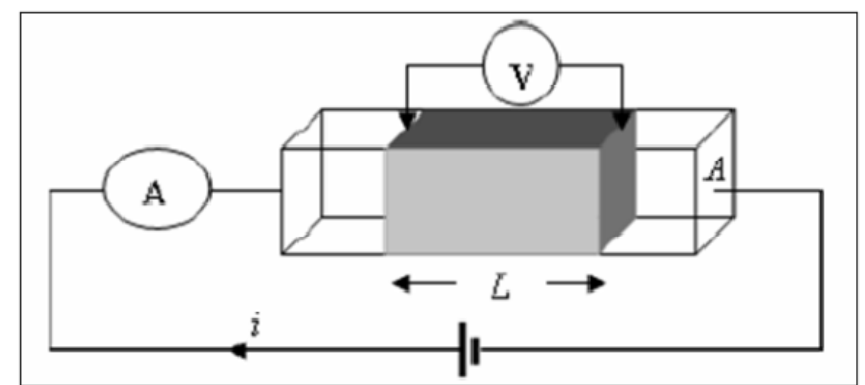

Gambar 4. Sebuah medium homogen dengan luas penampang A dan panjang $\mathrm{L}$, dialiri arus listrik $i$, beda potensial $v$ diukur di kedua ujung medium

Pengukuran di lapangan akan memiliki medium yang berbeda dengan konsep model homogen di atas. Hasil pengukuran di lapangan, nilai resistivitas semu yang akan terukur, tergantung dari keadaan medium/batuan yang terukur dan konfigurasi elektroda. Untuk memudahkan menghitung resistivitas dari batuan pada daerah pengukuran, maka dapat diasumsikan bahwa medium daerah pengukuran merupakan homogen isotrop.

\section{B. Konfigurasi Elektroda Dipole-dipole}

Konfigurasi dipole-dipole merupakan gabungan dari teknik profiling dan depth sounding, sehingga jenis konfigurasi ini merupakan salah satu konfigurasi yang umumnya digunakan dalam eksplorasi geofisika. Konfigurasi dipole-dipole menempatkan jarak elektroda arus C1C2 sama dengan jarak elektroda potensial P1P2, yang diperlihatkan pada gambar 5. Penempatan elektroda P1P2 berjarak $a$ dari pasangan elektroda $\mathrm{C} 1 \mathrm{C} 2$ dengan nilai faktor $n=1,2,3$. Nilai $K$ diturunkan ke persamaan (3), dengan nilai $n=1,2,3,4, \ldots, \mathrm{n}$.

(3)

$$
K=\pi \operatorname{an}(\mathrm{n}+1)(\mathrm{n}+2)
$$

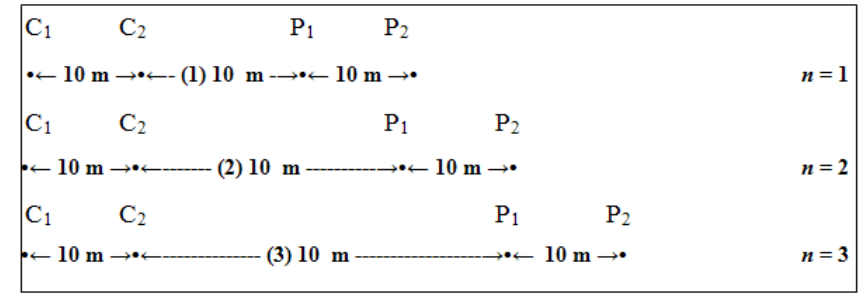

Gambar 5. Konfigurasi elektroda dipole-dipole dengan jarak elektroda C1C2 sama dengan P1P2 sebesar 10 meter dan jarak elektroda $\mathrm{C} 1 \mathrm{C} 2$ dari P1P2 sebesar 10 meter dikalikan dengan nilai $n$.

\section{METODOLOGI PENELITIAN}

\section{A. Lokasi Lintasan Penelitian}

Daerah penelitian meliputi wilayah perbukitan Kabungka dengan ketinggian 300 - 400 meter dpl, dalam wilayah Pasarwajo, Kabupaten Buton. Jumlah lintasan dalam penelitian ini adalah 10 lintasan, terdiri dari 9 lintasan berorientasi Tenggara - Baratlaut dan dihubungkan dengan 1 lintasan berorientasi Timurlaut - Baratdaya, memotong batas formasi dari daerah penelitian. Panjang lintasan $800-$ 5000 meter, spasi antar lintasan 200 meter. Orientasi lintasan dengan harapan didapatkan target berupa batuan aspal, karena ditemukan singkapan/rembesan aspal di permukaan. Lintasan 5 merupakan lintasan yang melewati singkapan dari asbuton, sehingga diharapkan acuan nilai resistivitas dari asbuton pada daerah penelitian. . Peta lintasan survey geolistrik diperlihatkan pada gambar 6 .

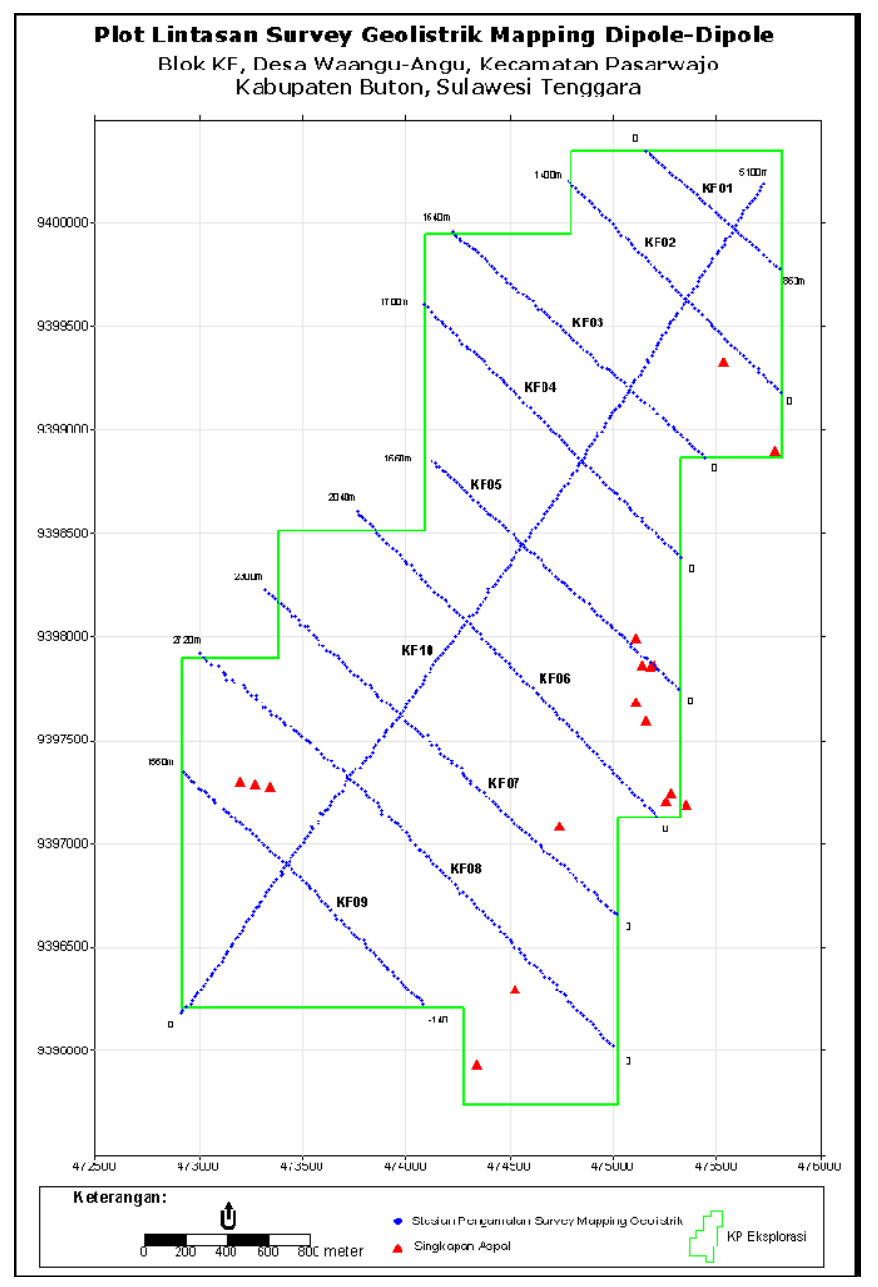

Gambar 6. Peta distribusi lintasan survey.

\section{B. Peralatan yang Digunakan}

Peralatan yang digunakan dalam penelitian ini adalah sebagai berikut :

1. Resistivitymeter OYO Model 2115A McOhm Mark-2

2. Booster untuk Resistivitymeter 
3. Peralatan pendukung, meliputi :

- 1 gulung meteran@400 meter

- 2 kabel gulung arus dan 2 kabel gulung potensial

- 2 elektroda arus

- 9 elektroda potensial berupa porous-pot

- 1 perangkat toolkit dan multimeter

- 1 buah GPS Garmin, kompas dan palu geologi

- handy-talk, buku lapangan dan alat tulis

- palu untuk elektroda

\section{Diagram Alir Penelitian}

Secara garis besar proses penelitian diperlihatkan pada diagram alir pada gambar 7 .

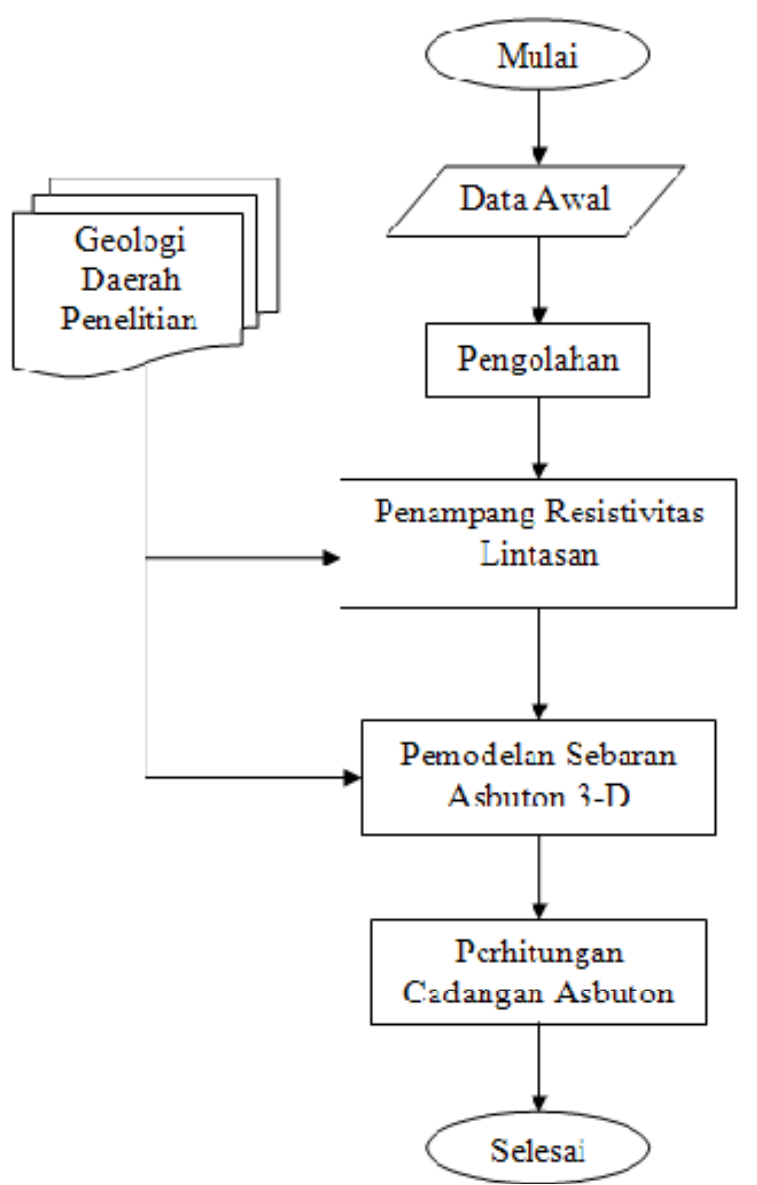

Gambar 7. Diagram alir penelitian.

D. Pemodelan Sebaran Asbuton 3-D

Hasil dari proses inversi tiap lintasan survey digabungkan dalam satu stack section. Penggabungan lintasan menggunakan perangkat lunak Surfer 8.0, dibuat menjadi suatu bentuk pemodelan secara 3-D. Perangkat lunak yang digunakan adalah RockWorks 2006 yang juga akan digunakan untuk menghitung volume asbuton. Model 3-D ini disebut juga solid model, yang adalah hasil interpolasi dari nilai-nilai resistivitas. Metode interpolasi menggunakan pendekatan nilai resistivitas yang menunjukkan keberadaan asbuton.

\section{HASIL DAN PEMBAHASAN}

A. Lokasi Penelitian

Lokasi penelitian merupakan daerah perbukitan dengan ketinggian berkisar $300-400 \mathrm{~m}$ dpl, dengan medan relatif beragam, diperlihatkan pada gambar 8, terdapat adanya lembah, puncak bukit dan dataran yang cukup luas.

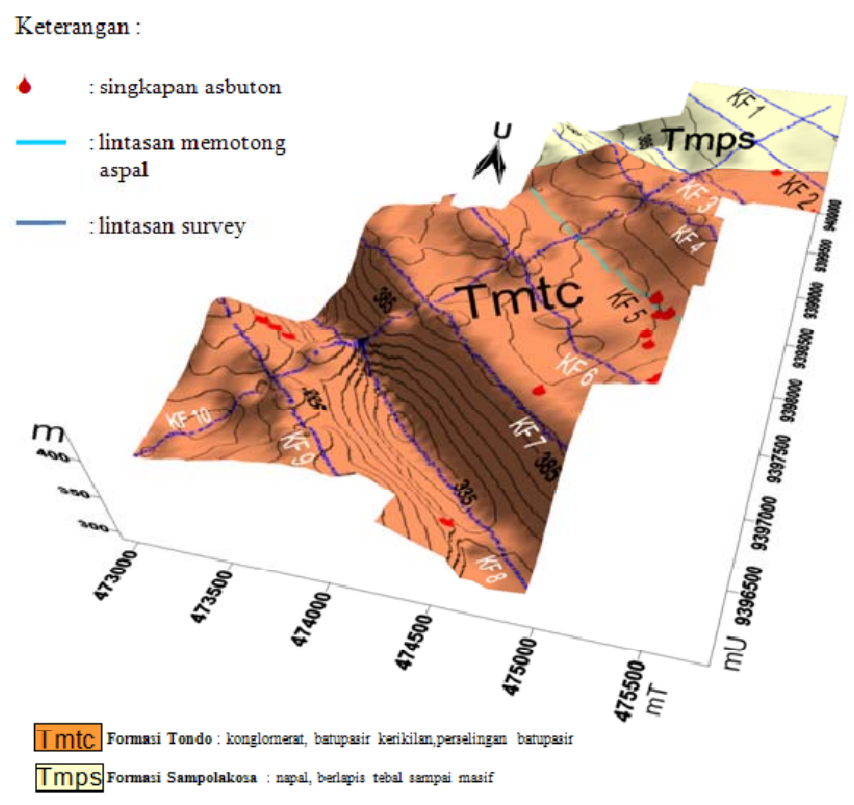

Gambar 8. Topografi daerah penelitian dan distribusi lintasan, serta formasi batuan yang ada.

\section{B. Penampang Resistivitas Lintasan}

1. Lintasan Acuan

Penentuan nilai resistivitas pada daerah penelitian yang berkorelasi dengan asbuton mengacu pada lintasan $5 \mathrm{~b}$, yang memotong singkapan asbuton. Proses inversi lintasan $5 \mathrm{~b}$ menghasikan nilai resistivitas dalam kisaran $90-600 \Omega \mathrm{m}$. Hasil proses inversi ditampilkan pada gambar 9 dan 10 .

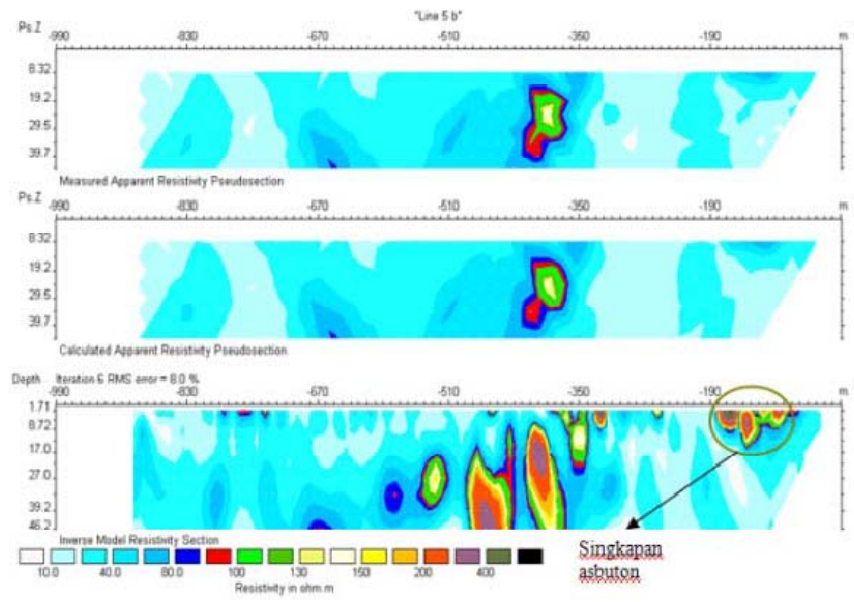


Gambar 9. Hasil pemodelan balik lintasan 5b yang melintasi singkapan batuan aspal

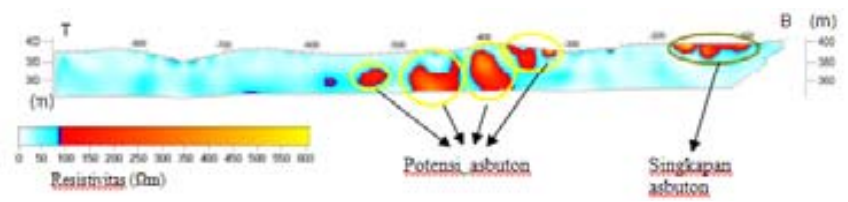

Gambar 10. Penampang resistivitas lintasan $5 \mathrm{~b}$ dan interpretasi keberadaan asbuton berdasarkan nilai resistivitasnya.

\section{Lintasan Memotong Batas Formasi}

Lintasan 3 merupakan lintasan yang memotong batas formasi antara Formasi Tondo dan Formasi Sampolakosa. Lintasan lain yang memotong kedua formasi adalah lintasan 2, 4, dan 10. Hasil pemodelan balik pada lintasan 3 memperlihatkan adanya zona batas kedua formasi pada meter ke 960 m, dengan pada Formasi Tondo yang berada di sebelah barat berada pada kawasan nilai resistivitas yang lebih tinggi karena mengandung batupasir, konglomerat dan batulempung di bandingkan dengan Formasi Sampolakosa yang berada di sebelah timur yang mengandung napal. Perbedaan tersebut diperlihatkan pada gambar 11 .

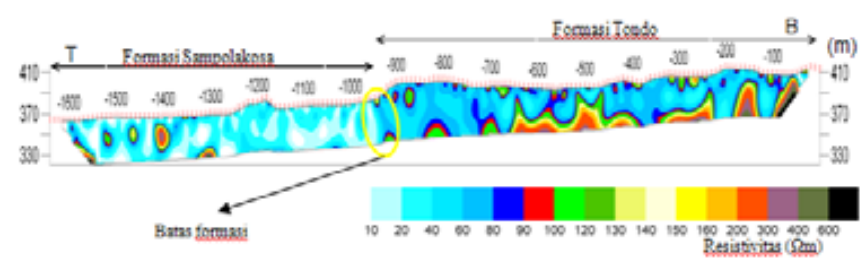

Gambar 11. Penampang resistivitas lintasan 3. Batas formasi diperlihatkan dengan perubahan pola nilai resistivitas.

\section{Lintasan dengan Potensi Cadangan Besar}

Lintasan 10a, memiliki potensi cadangan asbuton terbesar di antara lintasan lainnya. Lintasan 10a berada pada Formasi Tondo. Bentuk penampang resistivitas sebenarnya lintasan 10a diperlihatkan pada gambar 12 .

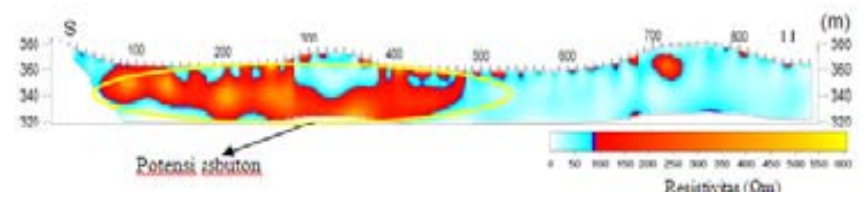

Gambar 12. Penampang resistivitas sebenarnya lintasan 10a yang memperlihatkan potensi asbuton yang besar.

\section{Pemodelan Sebaran Asbuton 3-D}

Pemodelan 3-D menggunakan masukan data sheet yang mempunyai 4 parameter yaitu $\mathrm{x}, \mathrm{y}, \mathrm{z}$, dan g. Koordinat UTM dimasukkan sebagai nilai $\mathrm{x}$ dan y yang menunjukkan posisi utara dan timur. Nilai z sebagai parameter kedalaman dan $g$ parameter nilai resistivitas sebenarnya. Nilai g akan mengacu pada nilai resistivitas sebenarnya di lintasan 5a, yakni pada nilai 90 - $600 \Omega \mathrm{m}$. Model 3-D ditampilkan dalam bentuk cadangan terukur dan cadangan tereka [9].

\section{Cadangan Terukur}

Cadangan terukur adalah penafsiran keberadaan model bawah permukaan dengan memperhitungkan sebaran nilai resistivitas sebenarnya ke arah lateral kiri dan kanan dari lintasan, yang dalam hal ini dengan jarak $20 \mathrm{~m}$. Pengacuan nilai tersebut diperhitungkan atas rata-rata besar model pada pseudodepth section masing-masing lintasan. Pemodelan potensi sebaran cadangan terukur asbuton 3-D diperlihatkan pada gambar 13 .

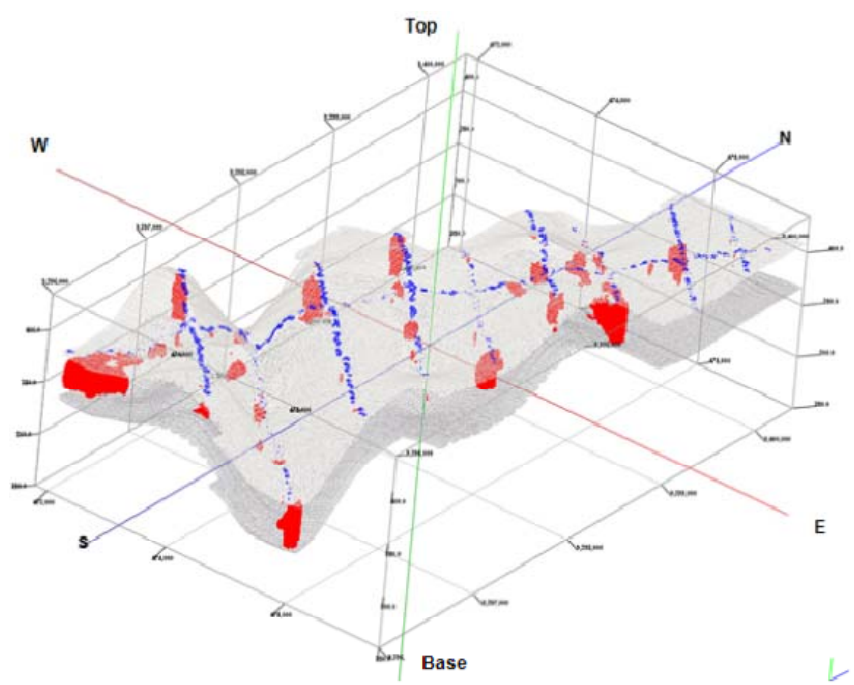

Gambar 13. Pemodelan potensi sebaran cadangan terukur asbuton 3-D dengan batas topografi dari arah tenggara.

\section{Cadangan tereka}

Cadangan tereka adalah penafsiran keberadaan model bawah permukaan dengan cara melakukan interpolasi nilai resistivitas sebenarnya pada software dengan arah lateral kiri dan kanan dari lintasan penelitian. Pemodelan potensi sebaran cadangan tereka asbuton 3-D diperlihatkan pada gambar 14.

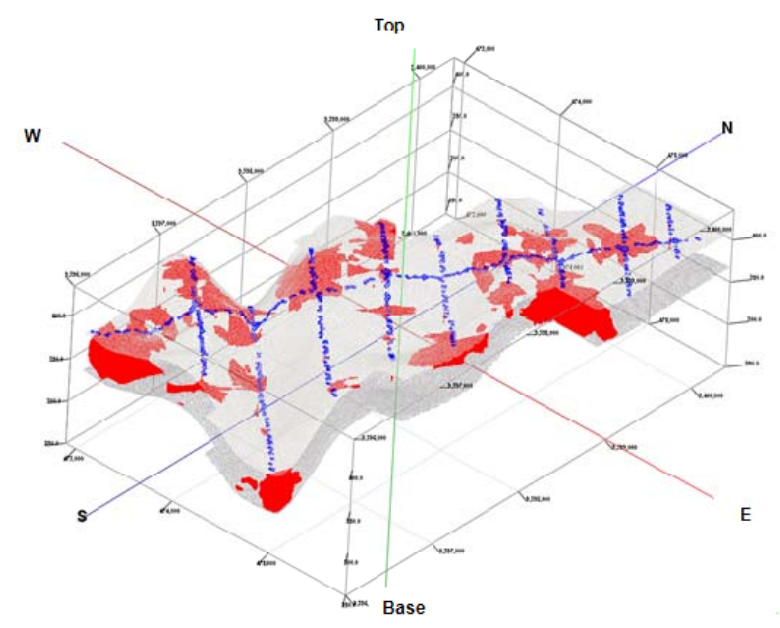


Gambar 14. Pemodelan potensi sebaran cadangan tereka asbuton 3-D dengan batas topografi dari arah tenggara.

D. Perhitungan Cadangan Asbuton

Hasil perhitungan potensi cadangan asbuton dengan menggunakan software RockWorks 2006 diperlihatkan pada gambar 15.

Dengan menggunakan densitas sebesar 2,8 ton $/ \mathrm{m}^{3}$, berikut adalah besar volume untuk tiap cadangan:

1. Cadangan terukur

$\begin{array}{ll}\text { Volume } & : 6,1 \text { juta meter kubik (m3) } \\ \text { Massa } & : 17,0 \text { juta ton }\end{array}$

2. Cadangan tereka

Volume : 22,2 juta meter kubik (m3)

Massa : 62,1 juta ton

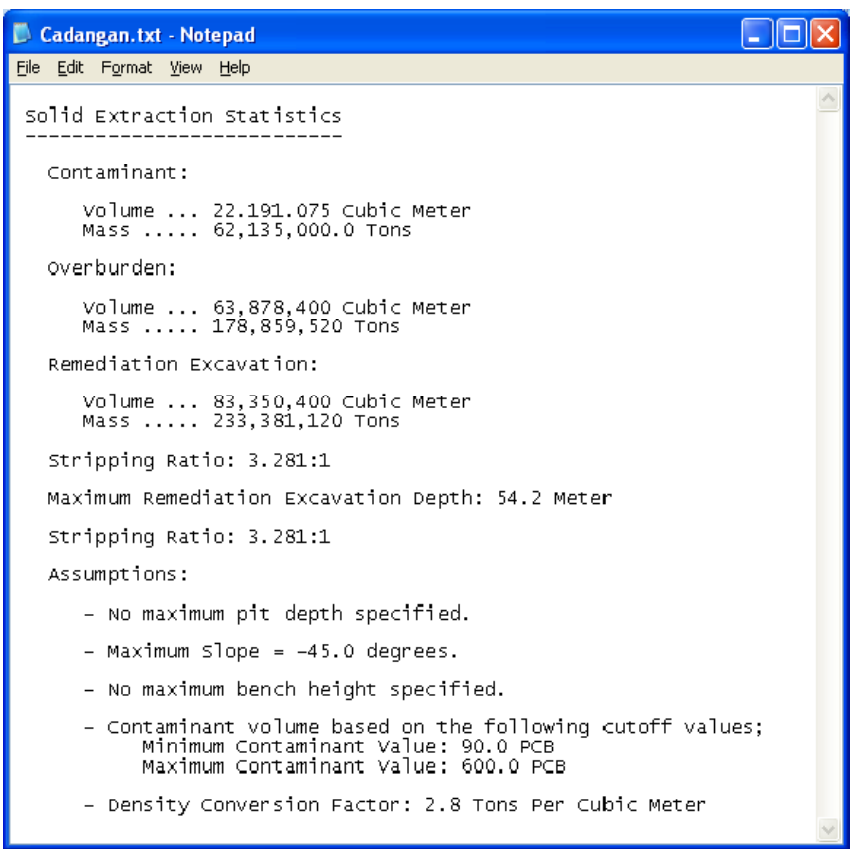

Gambar 15. Laporan hasil perhitungan volume dan massa cadangan asbuton menggunakan software RockWorks 2006 untuk cadangan tereka dengan volume total dari model 3-D adalah 83,4 juta $\mathrm{m} 3$, kedalaman maksimum adalah $54,2 \mathrm{~m}$, slope asbuton sebesar $45^{\circ}$, stripping ratio (perbandingan antara kepipihan bolder dengan lapisan tanah, semakin besar nilai stripping ratio maka semakin tebal lapisan tanahnya) sebesar 3,28: 1 dan batas resistivitas sebesar $90-600 \Omega \mathrm{m}$.

\section{KESIMPULAN}

Dari hasil analisis data resistivitas dipole-dipole untuk eksplorasi asbuton, maka dapat disimpulkan:

1. Penelitian data resistivitas dapat digunakan untuk memetakan sebaran asbuton, karena kontras nilai resistivitas asbuton dengan batuan sekitarnya nampak jelas, yaitu untuk batuan yang tidak mengandung aspal memiliki resistivitas yang rendah $(10-60 \Omega \mathrm{m})$ karena sebagian besar terdiri dari perlapisan napal yang tipis, batupasir yang memiliki kandungan air sedang. Besar nilai resistivitas batuan yang mengandung aspal (asbuton) adalah $90-600 \Omega \mathrm{m}$.

2. Potensi sebaran asbuton pada daerah penelitian banyak terdapat pada Formasi Tondo. Bentuk dari pemodelan asbuton adalah bolder yang di dalamnya terdapat perselingan antara napal, konglomerat, batupasir dan batulempung dengan ketebalan asbuton bervariasi antara $1-40$ meter.

3. Potensi cadangan asbuton adalah:

Cadangan terukur dengan volume sebesar 6,1 juta meter kubik dan massa sebesar 17,0 juta ton.

Cadangan tereka dengan volume sebesar 22,2 juta meter kubik dan massa sebesar 62,1 juta ton.

\section{PUSTAKA}

[1] Agus, M., 2006, Inventarisasi Bitumen Padat di Daerah Lelengka, Kabupaten Buton, Propinsi Sulawei Tenggara, Hasil-hasil Kegiatan Inventarisasi Bitumen Padat dan Gambut Tahun 2005. Dept. Energi dan Sumber Daya Mineral.

[2] Astjario, P., 2008, Kecepatan Pengangkatan Pulau Buton dan Jejak Perubahan Muka Air Laut di Zaman Kuarter, Artikel Puslitbang Geologi Kelautan

[3] Hamzah, M., 2001, Eksplorasi Aspal Batu Buton (Asbuton) dengan Metode Geolistrik, Thesis Jurusan Teknik Geofisika ITB : Bandung.

[4] Sikumbang, N., Sanyoto, P., Supandjono, R. J. B. dan Gafoer, S., 1995, Peta Geologi Lembar Buton, Sulawesi Tenggara skala 1 : 250.000. Pusat Penelitian Dan Pengembangan Geologi.

[5] Sudrajat, A., 1988. Bahan Galian Aspal, Bahan Galian Industri. Pusat Penelitian dan Pengembangan Teknologi Mineral.

[6] Telford, W.M., Geldart, L.P., Sheriff, R.E. and Keys, D.A., 1976, Applied Geophysics II, Cambridge University Press.

[7] Tobing, S. M., 2005, Inventarisasi Bitumen Padat di Daerah Sampolawa, Kabupaten Buton, Propinsi Sulawei Tenggara, Hasil-hasil Kegiatan Inventarisasi Bitumen Padat dan Gambut Tahun 2005. Dept. Energi dan Sumber Daya Mineral.

[8] http://kimia.upi.edu

[9] www.dim.esdm.go.id

[10] www.maps.google.com 